\title{
On the corrosion of ZK60 magnesium alloy after severe plastic deformation
}

\author{
D. Merson ${ }^{1}$, E. Vasiliev ${ }^{1}$, M. Markushev ${ }^{2}$, A. Vinogradov ${ }^{1,3, \dagger}$ \\ †alexei.vinogradov@ntnu.nu \\ ${ }^{1}$ Togliatti State University, Belorusskaya st., 14, Togliatti, 445020, Russia \\ ${ }^{2}$ Institute for Metals Superplasticity Problems of RAS, S. Khalturina st., 39, Ufa, 450001, Russia \\ ${ }^{3}$ Norwegian University of Science and Technology, 7491 Trondheim, Norway
}

\begin{abstract}
Magnesium alloys are promising materials for the surgical implants due to their exceptional mechanical properties, biocompatibility and biodegradability. Binary Mg-Zn and ternary Mg-Zn-Zr alloys are the most obvious candidates for further design of biomaterials. However, they have to meet many requirements, including high strength and corrosion performance. In this work, we demonstrate that the corrosion resistance of the alloy Mg-6Zn-0.5Zr (ZK60) can be controlled to a large extent by its microstructure and distribution of phases, formed by thermomechanical treatment involving hot severe plastic deformation (SPD). The two-step multi-axial isothermal forging (MIF) is employed to deform the alloy ZK60 to different strains at $400^{\circ} \mathrm{C}$ and $300^{\circ} \mathrm{C}$. The influence of microstructural parameters on the corrosion rate is demonstrated. It was found that MIF leads to the microstructure refinement, increases the fraction of high-angle grain boundaries, and reduces the size and distribution inhomogeneity of the second phases, thus promotes the formation of a reasonably uniform protective layer at the surface, and increases the overall corrosion resistance of the investigated ZK60 alloy. The homogeneous microstructure fabricated by MIF plays an important role for corrosion resistance since any heterogeneity or bi-modality of grain boundary structure can lead to large gradients of the driving force for oxidation within the material, and, as a consequence, to the difference in the spatial properties and the heterogeneity of the protective oxide film. With the observed reasonable corrosion performance and excellent mechanical properties, the fine-grained alloy ZK60 manufactured by hot two-step MIF processing has a great potential for bio-medical applications as a material for bio-resorbable implants or vascular stents.
\end{abstract}

Keywords: magnesium alloys, corrosion rate, severe plastic deformation, microstructure.

\section{Introduction}

Since recently magnesium is considered as a promising candidate for use in surgical implants. Magnesium has many superior characteristics required for biomaterials: first of all - biocompatibility, non-toxicity and absence of allergic or carcinogenic properties. However, the main feature and a property of interest of magnesium in comparison with other materials used in orthopedic practice - stainless steel, titanium alloys, cobalt-based alloys, etc. - is its bioresorbability, which refers to the capacity to be absorbed naturally into the human body. Thus, in orthopedic surgery, after the consolidation of bone fragments, there is no need for repeated surgical intervention to remove the implants, which reduces the traumatic effect and increases the efficiency of medical treatment. However, from a medical point of view, it is desirable that a temporary implant is present in the human body for more than 12 weeks, so that the bone tissue is completely restored, and then it must degrade gradually [1]. This poses a number of requirements to the properties any temporary implant material must meet. These include (i) mechanical properties, (ii) biocompatibility and (iii) biodegradability with a desired rate.
Magnesium has a high specific strength and low elastic modulus, which is close to that for the cortical bone layer. Despite many advantages, the main factor impeding applications of magnesium and its alloys as biomedical materials is their high corrosion rate. Magnesium has a high negative standard electrode potential of $-2.34 \mathrm{~V}$ compared to the normal hydrogen electrode potential (NHE) at $25^{\circ} \mathrm{C}$ [2]. It corrodes much faster than other metallic materials, especially in an aqueous medium containing chlorine $\mathrm{Cl}$ anions including naturally in the physiological fluids or blood plasma of the human body. Since pure magnesium does not meet the mutually exclusive requirements for the properties necessary for medical applications, it is necessary to develop an alloy with a suitable corrosion resistance and to manage its microstructure for optimal performance. The procedures, which can be employed to tailor the structure of the magnesium alloys, are well known within the framework of classical materials science and these include (i) changing the chemical composition by alloying, (ii) changing the microstructure by heat treatment and (iii) changing the microstructure by preliminary plastic deformation (the forth way - modifying the surface of the magnesium alloy - is not considered in the present paper). 
Considering the chemical composition, the choice of alloying elements is extremely limited by the requirements of biocompatibility and technological feasibility. On the one hand, this narrows the circle of applicants in the design of alloys. On the other hand, it does not make it possible to realize the maximum desired strength and ductility by chemical design due to the specific of the resulting strengthening phases, their morphology, distribution and chemical composition [3]. The latter, in turn, are frequently the root cause of poor corrosion properties [4,5]. Besides, secondary phases and intermetallic compounds complicate further the deformation processing (which is not simple for magnesium anyway) aimed at microstructure refining and forming a favorable crystallographic texture [6,7]. The use of rare earth elements [8] or lithium [4] allows to significantly reduce the corrosion rate and increase the mechanical properties $[9,10]$, but increases the risk of unexpected negative implications for patients. Therefore, the active search for the optimal chemical composition is still being continued up to date [11 - 14].

Binary magnesium alloys $\mathrm{Mg}-\mathrm{Zn}$, consisting entirely of bio-compatible elements, are the most obvious candidates for further design of biomaterials [15]. Although addition of calcium helps improve the corrosion resistance of magnesium alloys [16], the mechanical properties (tensile strength and elongation) of $\mathrm{Mg}$-Ca alloys are unsatisfactory for implants. For instance, the strength and elongation in the cast $\mathrm{Mg}-1 \mathrm{Ca}$ alloy are $71.38 \pm 3.01 \mathrm{MPa}$ and $1.87 \pm 0.14 \%$, respectively. Corrosion resistance of these alloys also leave a lot to desire $[17,18]$. Some Mg-Zn alloys can have a fine microstructure leading to a good enough tensile strength about $250 \mathrm{MPa}$ and ductility (of $20 \%$ elongation) $[19,20]$. Taking into account a good biocompatibility in vivo and non-toxicity, $\mathrm{Mg}$ - $\mathrm{Zn}$ alloys appear to be viable candidates for use as biomedical materials (e.g. as vascular stents) [21]. Many tertiary $\mathrm{Mg}-\mathrm{Zn}-\mathrm{X}$ alloys exhibit improved mechanical properties with $\mathrm{Zn}$ concentration of $1-6 \%$ and less than $1 \%$ of the additional $\mathrm{X}$-component. A very popular modifier of the structure of $\mathrm{Mg}$ alloy is $\mathrm{Zr}$, which acts as a grain-refining agent, alloy purifier reducing the concentration of harmful Fe impurities and strengthening element due to various $\mathrm{Zr}$-containing intermetallic compounds forming in $\mathrm{Mg}-\mathrm{Zn}-\mathrm{Zr}$ alloys [22]. For this reason, we have chosen the "classic" commercial $\mathrm{Mg}-\mathrm{Zn}$-Zr alloy ZK60 for the present work.

The synergy of the classical processing-structure (composition)-properties triad of materials science is to provide the required level of a complex of functional properties, including mechanical strength, plasticity and fatigue endurance an $[23,24]$, a sufficiently low rate of bioresorption to maintain the integrity of the entire implant design during osteosynthesis, with no toxicity and good biocompatibility. The key properties that require in-depth understanding and improvement for practical application in medicine are the corrosive behavior of alloys with different chemical composition and structural characteristics, as well as fatigue strength in a corrosive environment. The increase in strength and fatigue properties is usually achieved by alloying due to solid solution and precipitation strengthening and/or by grain refinement leading to Hall-Petch grain boundary strengthening. The issue which has not been addressed sufficiently to date is the influence of deformation treatment on functional properties of $\mathrm{Mg}$ alloys.

Over the recent years, severe plastic deformation (SPD) techniques have been shown quite efficient for modifying the microstructure and strengthening of metallic materials by grain refinement [25]. On the other hand, Vinogradov et al. [26] have demonstrated that integrated SPD processing involving direct extrusion combined with two equal channel angular pressing passes is effective for improving the high cycle fatigue performance of the ZK60 alloy in parallel with enhanced galvanic corrosion resistance [27].

Thus, the objective of the present work is to determine the effect of thermo-deformation treatment, involving severe plastic deformation via one of the most effective bulk materials processing - multistep isothermal forging (MIF), on microstructure refinement for the corrosion resistance of the popular magnesium alloy $\mathrm{Mg}-\mathrm{Zn}-\mathrm{Zr}$, which is often considered as a candidate for bio-medical applications.

\section{Experimental procedure}

The billets of the alloy ZK60 (nominal composition $\mathrm{Mg}-6 \mathrm{Zn}-0.5 \mathrm{Zr}$, in wt.\%) with dimensions $70 \times 70 \times 170 \mathrm{~mm}^{3}$ were subjected to MIF at $400^{\circ} \mathrm{C}$ from a hot-pressed rod in T6 condition. On the second step, MIF was performed at $300^{\circ} \mathrm{C}$. During processing, the billet experienced six deformation cycles on each step involving a sequence of settings and drawings with axis changing as described in [28]. The total true strain imparted on a working billet at the first step was of 4.2 and 3.0 at the second. The last deformation cycle at each step was ended by oil cooling. The pure $4 \mathrm{~N} \mathrm{Mg}$ and coarse grain alloy ZK60 (both in the as-cast state) were used for comparison.

The alloy microstructure was analyzed in the longitudinal plane of the billets in the field emission gun scanning electron microscope (SEM) Zeiss Sigma equipped with the electron back scattering diffraction (EBSD) detector (EDAX/TSL) and orientation image microscopy (OIM) software package. Prior to microstructural analysis, the samples were mechanically polished to a mirror-like finish and then electrolytically polished in $90 \%$ ethanol $+10 \%$ nitric acid solution.

Various methods, which are widely used to characterize corrosion properties and to investigate the mechanism of corrosion processes, include a family of potentiostatic and dynamic electrochemical methods, impedance spectroscopy, etc. Due to the specific in Mg-rich alloys negative difference effect (the electrochemical phenomenon that anodic stimulation facilitates hydrogen discharge to a greater extent than cathodic polarization [29]), significant errors can arise in corrosion rate measurements when using traditional electrochemical techniques [30]. Therefore, the weight-loss rate method, which has been regarded as the most basic and reliable method, is still used as a "golden standard" corrosion test. Corrosion rate was measured by gravimetric method whereby metal coupons were exposed to the test medium (pure Salina, which is commonly used in a wide variety of molecular and cellular biology applications) and measure the 
loss of weight of the material. The plate specimens with the surface are of $650-800 \mathrm{~mm}^{2}$ were grinded by a sand paper down to \#2500 grade, washed in the ultrasonic bath with acetone, dried and weighted on the analytical balance with the accuracy of $0.0001 \mathrm{~g}$. They were then immersed into $0.9 \%$ sodium chloride $(\mathrm{NaCl})$ distilled water solution $(\mathrm{pH}=7.4)$ for $24 \mathrm{~h}$ at $25^{\circ} \mathrm{C}$ and following removal, the specimens were dried by hot air. The corrosion products were removed from the surface by the solution containing $200 \mathrm{~g}$ of $\mathrm{CrO}_{3}, 10 \mathrm{~g}$ of $\mathrm{AgNO}_{3}$ and $1000 \mathrm{~cm}^{3}$ of distilled water at $20-25^{\circ} \mathrm{C}$. The specimens were then immediately weighted again.

The surface topology after corrosion testing was examined by the confocal laser scanning microscope Olympus Lext OLS4000 microscope complemented by SEM observations using the Sigma and JEOL JCM-6000 microscopes. Powder $\mathrm{X}$-ray diffraction (XRD) analysis was performed on a Shimadzu X-ray diffractometer (XRD-7000S) in the $\theta-2 \theta$ mode, with a $\mathrm{CuK}_{\alpha}$ radiation source $(40 \mathrm{kV}$ and $40 \mathrm{~mA})$ aiming at identification of the secondary phases.

\section{Results}

Typical SEM images in back-scattered electron (BSE) contrast revealing the grain structure of pure $\mathrm{Mg}$, the as-cast (reference) ZK60 and MIF-processed alloys are shown in Fig. 1. Pure $\mathrm{Mg}$ and the as-cast alloy have a rather homogeneous grain distribution, Fig. 1a, with grain sizes determined by the standard intercept as shown in Table 1 . The cast ZK60 alloy is characterized by a coarsegrain $\alpha-\mathrm{Mg}$ matrix with second phases decorating grain boundaries and triple junctions, as illustrated in Fig. 1b. The XRD analysis identifies this major excess phase with $\mathrm{MgZn}_{2}$ (Fig. 2). The MIF-processed alloys exhibit partially recrystallized fine-grained microstructure. Since MIF has been performed at high (for $\mathrm{Mg}$ ) homologous temperature, the main mechanism of grain refinement is associated with dynamic recrystallization (DRX) giving rise to very fine equiaxed grains from 1 to $10 \mu \mathrm{m}$ size. However, since DRX has not been completed during the first step MIF processing at $400^{\circ} \mathrm{C}$ it results in the very heterogeneous grain structure consisting of fine recrystallized grains and coarse (several tens or even hundred micrometers size) initial grains embedded in the cloud of finer grains, Fig. 1c and 3a. The bimodality of grain distribution in this case is particularly clear from the EBSD maps shown in Fig. 3 revealing the grain microstructure and in the inverse pole figure colors for both MIF-processed samples. The microstructure after two step MIF (at $400^{\circ} \mathrm{C}+300^{\circ} \mathrm{C}$ ) was much more homogeneous grain structure consisted of fine, equiaxed grains with a volume fraction of $75 \%-80 \%$, (Fig. 1d and $3 \mathrm{~b}$ ), although it still cannot be regarded as a completely uniform. The overall grain size distribution in all cases was found to be log-normal with the mean values and errors show in Table 1. Thus, the considerable grain refinement occurred due to SPD as is reasonable expected and reported formerly also in $[28,31-33]$. Besides, it has been found that the distribution of $\mathrm{Mg}-\mathrm{Zn}$ excess phases and precipitates is retained in the MIF-processed billets, though the size of secondary phases is much smaller that it is seen in Fig. $1 \mathrm{~b}$ and their distribution is more uniform.

Corrosion rates are shown in Table 1 . One can see that pure $\mathrm{Mg}$ demonstrates the worst corrosion resistance, which is improved reasonably with $\mathrm{Zn}$ addition for the alloy ZK60. In the as-cast condition, the alloy possesses the corrosion resistance which is also far below expectations. However, the corrosion properties improve progressively with grain refinement and homogeneous structure formation in the hotMIF-fabricated specimens.
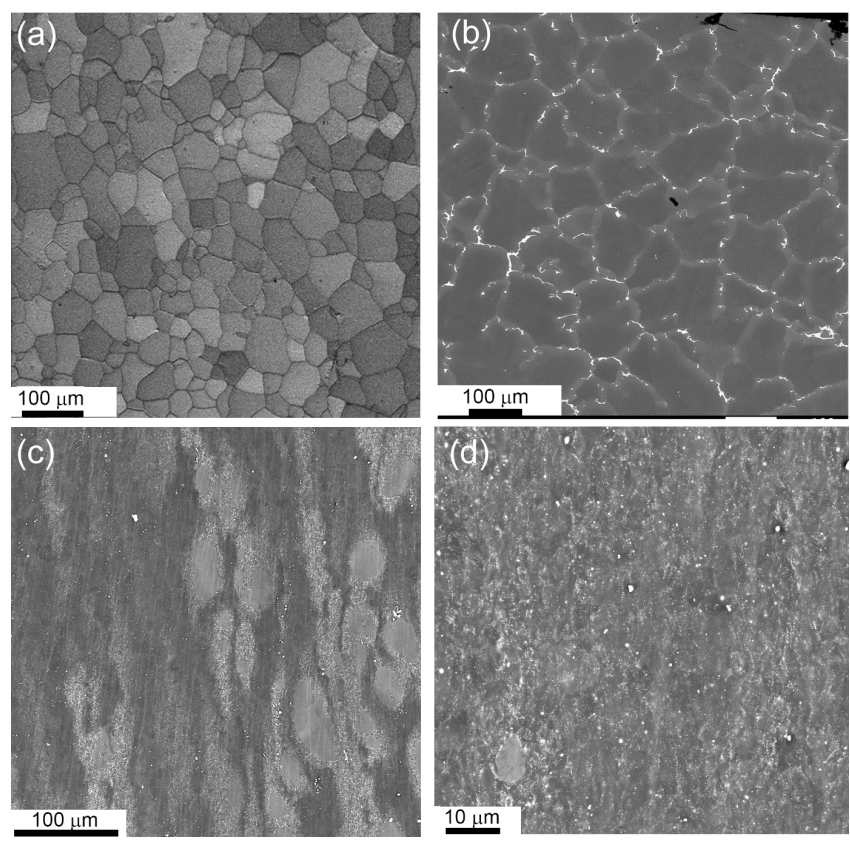

Fig. 1. SEM images showing the grain structure of pure Mg (a), ZK60 as-cast alloy (b), ZK60 alloy after MIF at $400^{\circ} \mathrm{C}$ (c) and ZK60 alloy after two step MIF at $400^{\circ} \mathrm{C}$ followed by MIF at $300^{\circ} \mathrm{C}$ (d).

Table 1. Corrosion properties of $\mathrm{Mg}$ alloys tested

\begin{tabular}{|c|c|c|c|c|c|}
\hline \multirow{2}{*}{ Alloy } & \multirow{2}{*}{ Grain size, $\mathrm{d}(\mu \mathrm{m})$} & \multirow{2}{*}{ Corrosion rate, $(\mathrm{mm} /$ year $)$} & \multicolumn{3}{|c|}{ Surface roughness $(\mu \mathrm{m})$} \\
\cline { 3 - 6 } & & & $\mathrm{Sa}$ & $\mathrm{Sz}$ & $\mathrm{Sq}$ \\
\hline Pure Mg (cast) & $5000 \pm 450$ & $16.4 \pm 4.4$ & 108 & 586 & 135 \\
\hline $\mathrm{ZK60}$ (cast) & $123 \pm 12$ & $4.6 \pm 0.9$ & $\mathrm{n} / \mathrm{a}^{*}$ & $\mathrm{n} / \mathrm{a}^{*}$ & $\mathrm{n} / \mathrm{a}^{\star}$ \\
\hline $\mathrm{ZK} 60 \mathrm{MIF} 400^{\circ} \mathrm{C}$ & $7.1 \pm 0.4$ & $3.3 \pm 1.4$ & 34 & 376 & 54 \\
\hline $\mathrm{ZK} 60 \mathrm{MIF} 400^{\circ} \mathrm{C}+300^{\circ} \mathrm{C}$ & $5.0 \pm 0.3$ & $2.6 \pm 0.5$ & 32 & 266 & 42 \\
\hline
\end{tabular}

${ }^{*} \mathrm{n} / \mathrm{a}-$ data is not available 


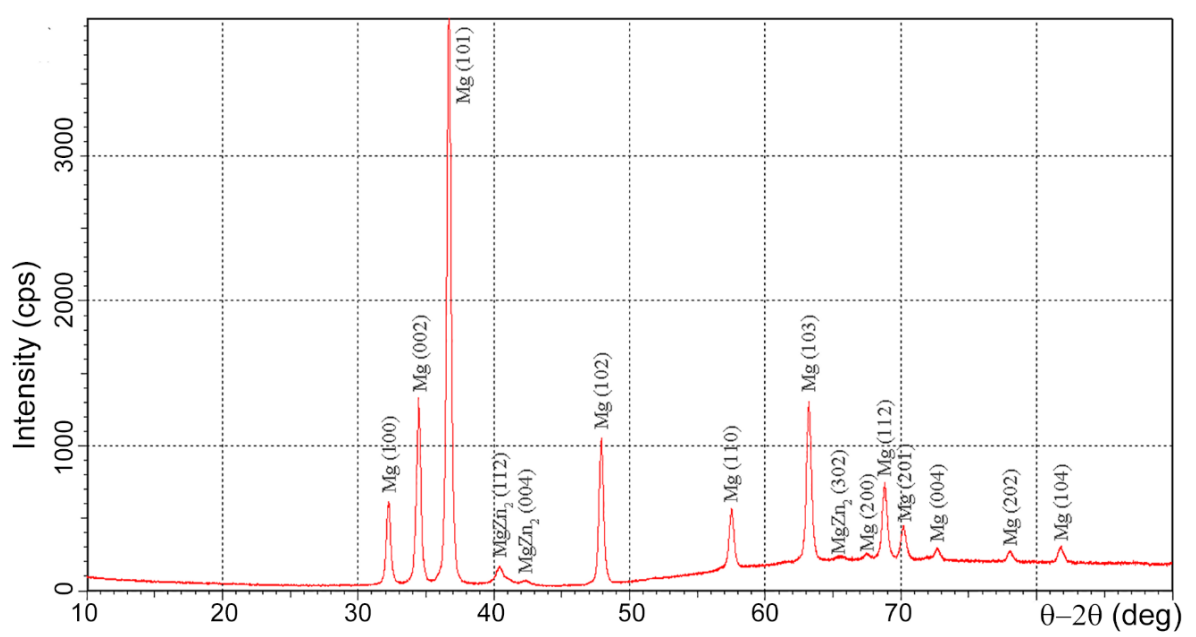

Fig. 2. Results of the XRD scan of the alloy ZK60 after MIF performed at $400^{\circ} \mathrm{C}$.

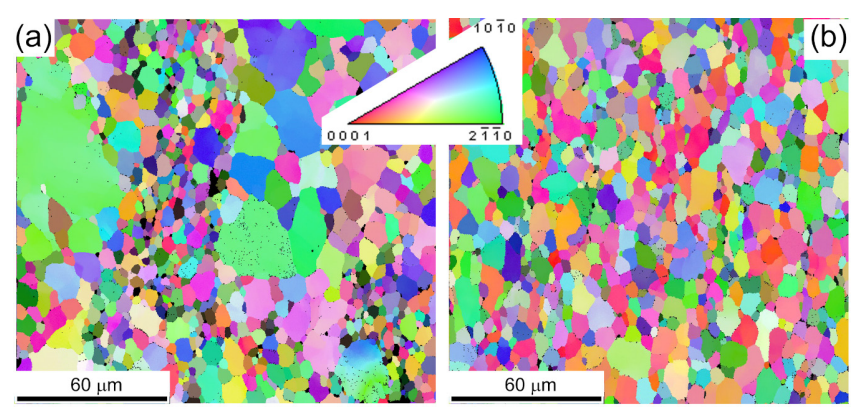

Fig. 3. (Color online) Orientation image microscopy (EBSD) maps in the inverse pole figure colors (the color legend is shown in the inset) for the fine-grain ZK60 alloy after MIF at $400^{\circ} \mathrm{C}$ (a) and ZK60 alloy after two step MIF at $400^{\circ} \mathrm{C}$ followed by MIF at $300^{\circ} \mathrm{C}$ (b).

The surface topology assessed by CLSM and SEM for the specimens after immersion into Salina solution for $24 \mathrm{~h}$ is shown in Figs. 4 through 7, correspondingly. It can be seen in CLSM images $(a, b)$ that the corrosion products deposited on the surface are heterogeneously distributed and do not provide the full protection to the surface layer. This is particularly true for pure $\mathrm{Mg}$, which showed the worst corrosion behavior. Upon obtaining the $3 \mathrm{D}$ surface topology map by CLSM after corrosion product removal, the surface roughness parameters Sa (the arithmetical mean height), $\mathrm{Sz}$ (the maximum peak height defined as the sum of the largest peak height value and the largest pit depth value within the defined area), and Sq (the standard deviation of heights) were calculated as summarized in Table 1 . The very rough surface in pure $\mathrm{Mg}$ is observed because some grains were selectively etched, indicating possibly the orientation effect of the corrosive attack showing that preferential crystallography exists for primary corrosion degradation. Once the magnesium or its alloy surface contacts with the physiological solution, an electric double layer is formed. The chloride ions available in the solution penetrate into the electric double layer and electrochemically react with the alloy matrix, causing pitting corrosion which obviously manifests itself as the main degradation mechanism. It is most evident for the alloy ZK60 in the as-cast condition, Fig. 5. The poor corrosion performance of the as-cast alloy is explained by the coarse excess phases distributed along the grain boundaries. Being the anodic sites and causing the electrochemical cells with the matrix they appear to be the preferred sites for the localized corrosive attack. Finally, intergranular corrosive grooves form on the surface of the as-cast alloy.

After the samples were removed from the test solution and dried, the corrosion product protective layer is dehydrated, forming a network of surface cracks, which are clearly visible on all surfaces and which represent the typical degradation pattern in this class of alloys [34]. Usually, the thicker the corrosion product layer, the more severe the cracking is [34]. The morphology and distribution of corrosion products on the surface of specimens after two versions of MIF processing does not differ appreciably, c.f. Figs. 6 and 7 (a,b). However, the finer grain alloy with a more uniform microstructure demonstrates a remarkably lower corrosion resistance and smaller surface roughness.

\section{Discussion}

Ullmann et al. [35] have shown that, in full agreement with the early works [36,37], grain refinement in magnesium alloys exerts a beneficial effect on corrosion properties due to more uniform corrosion and a blurred area of grain boundaries, in which the most active corrosion is expected. The results obtained are also in good qualitative agreement with the recent findings by Lin et al. [38] on the alloy of the same nominal composition manufactured by hot extrusion at different rates. It was observed that the samples with the inhomogeneous microstructure (even with a small volume fraction of non-recrystallized grains) exhibited markedly worse corrosion resistance (although the corrosion properties were characterized indirectly estimated by electrochemical methods).

An interesting observation is that the high density of grain boundaries in Magnesium can act as barriers against the rapid spread of corrosion [39]. Mg alloys tend to form a protective oxide layer inhibiting extensive oxidation $[40,41,42]$. It has been recognized that the grain boundary is the place that is particularly susceptible to easy oxidized and that a high density of defects or grain boundaries promotes 

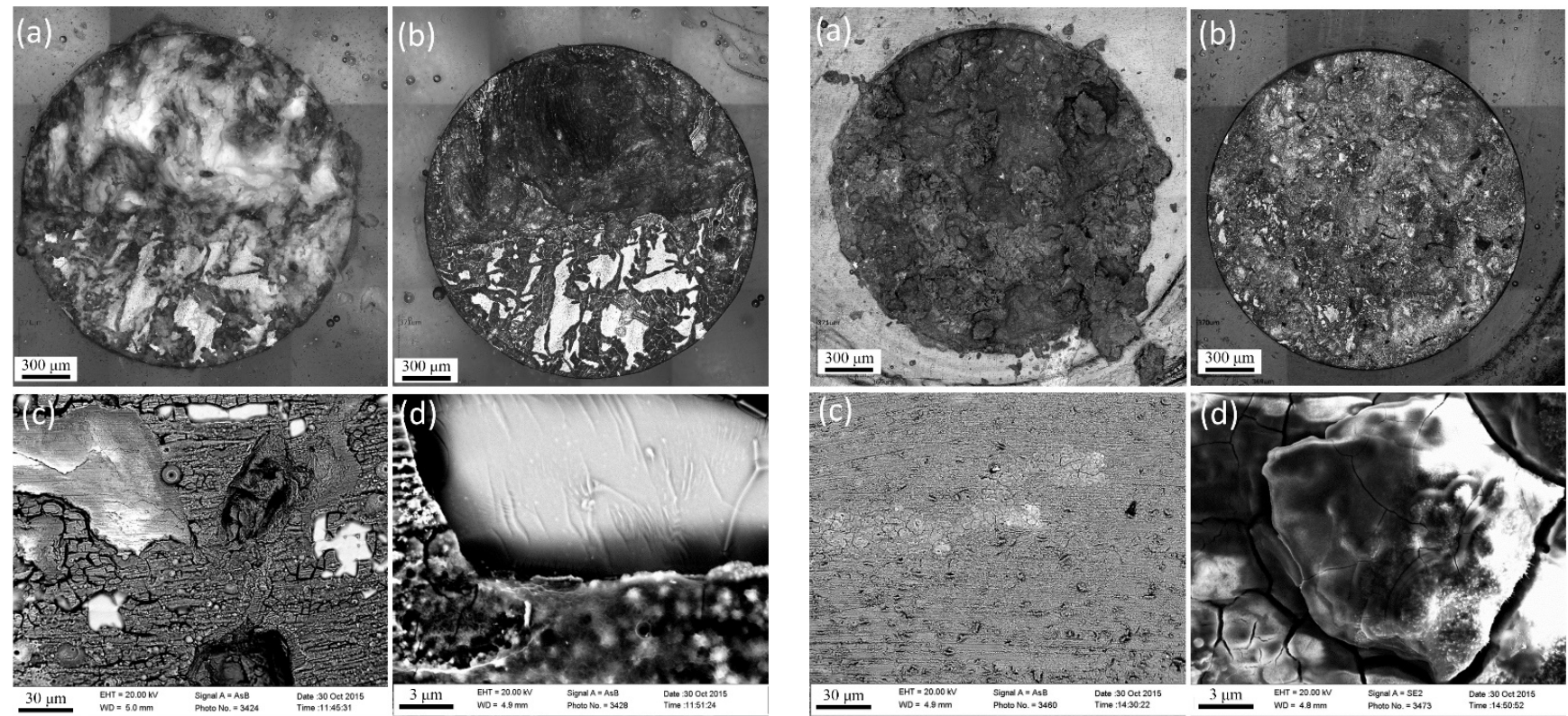

Fig. 4. CLSM images showing the surface of the pure $\mathrm{Mg}$ specimens immediately after the corrosion test (a) and after corrosion product removal (b). SEM images showing typical surface morphology after environmental degradation (c) and (d) at different magnifications. Note that some grains are particularly prone to corrosive attack.
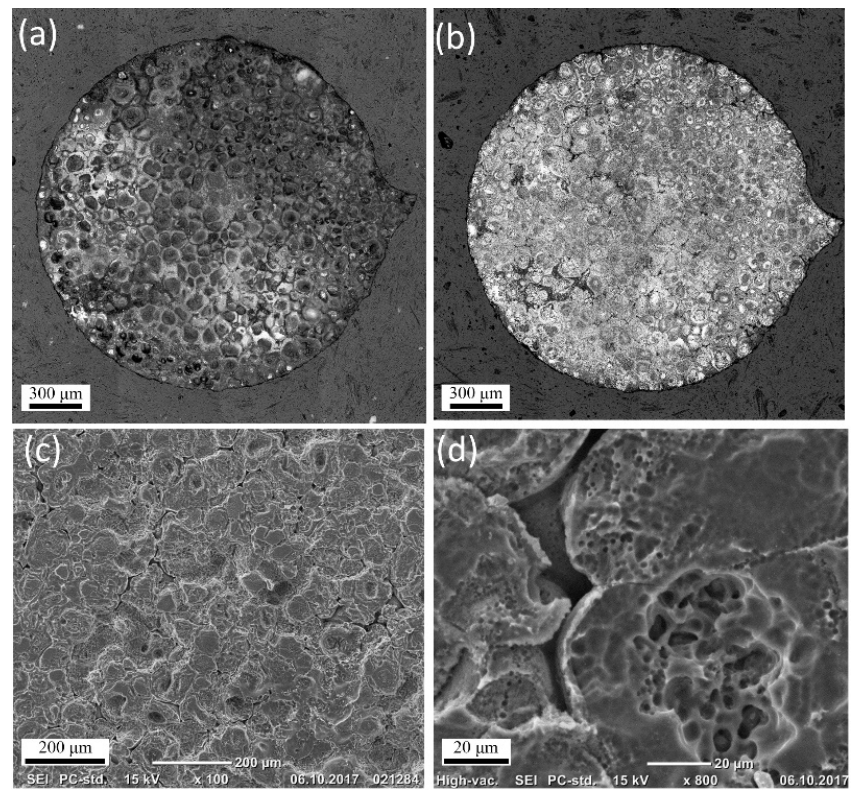

Fig. 5. CLSM images showing the surface of the as cast ZK60 alloy specimens immediately after the corrosion test (a) and after corrosion product removal (b). SEM images showing typical surface morphology after environmental degradation (c) and (d) at different magnifications. Note the dominance of pits and intercrystalline cracks.

the formation of an oxide film, which effectively prevents the penetration of the corrosive medium. The bimodal grain boundary structure leads to large differences in the driving force for oxidation at different points of the material, and, as a consequence, to the difference in the spatial properties and the heterogeneity of the protective oxide

Fig. 6. CLSM images showing the surface of the MIF $\left(400^{\circ} \mathrm{C}\right)$ fabricated alloy ZK60 immediately after the corrosion test (a) and after corrosion product removal (b). SEM images showing typical surface morphology after environmental degradation (c) and (d) at different magnifications. Note the dominance of network cracks in the oxide film.
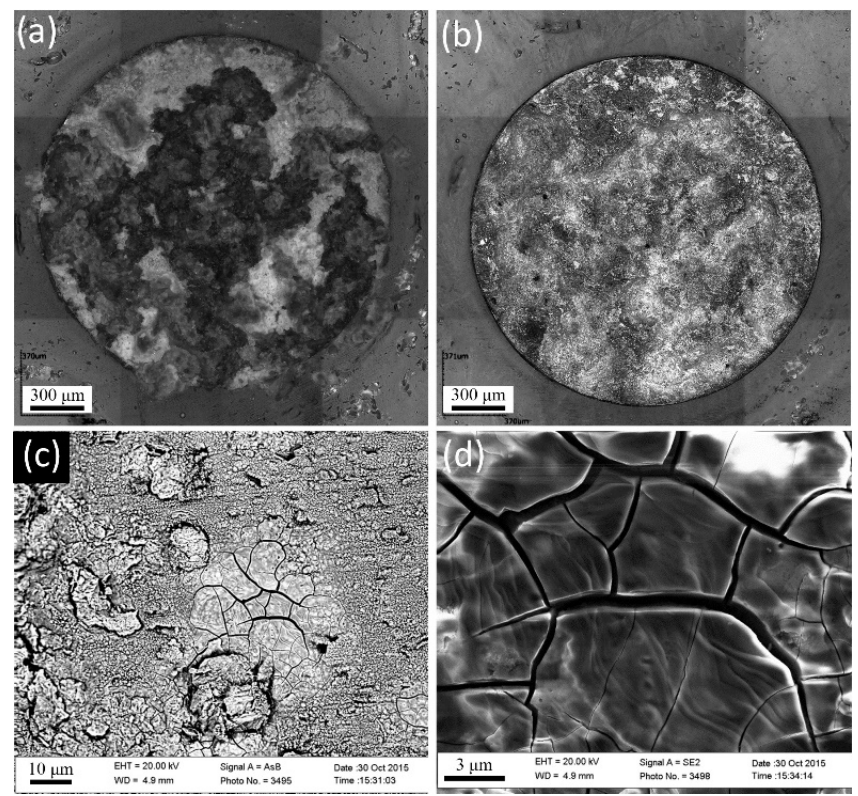

Fig. 7. CLSM images showing the surface of the two step MIF $\left(400^{\circ} \mathrm{C}\right.$ and $300^{\circ} \mathrm{C}$ ) fabricated alloy ZK60 immediately after the corrosion test (a) and after corrosion product removal (b). SEM images showing typical surface morphology after environmental degradation (c) and (d) at different magnifications. Note the dominance of network cracks in the oxide film.

film. The latter, therefore, appear ineffective in protecting against the aggressive environment, especially the regions of large grains, particularly if they are favorably orientated. Moreover, it is important that Lin et al. have demonstrated that cyto-compatibility was also improved in samples with an optimized homogeneous microstructure [38]. 
With the reasonable corrosion performance and excellent mechanical properties - monotonic yield stress of $230 \mathrm{MPa}$, ultimate strength exceeding $320 \mathrm{MPa}$ paired with superior ductility over $30 \%$ and uniaxial fatigue limit of $110 \mathrm{MPa}$ $[7,43]$, the fine-grained alloy ZK60 manufactured by hot two-step MIF processing under the temperature decreasing from $400^{\circ} \mathrm{C}$ to $300^{\circ} \mathrm{C}$ between the steps has a great potential for bio-medical applications as a material for bio-resorbable implants or vascular stents. It also has the potential for genetic improvement of properties by purification of initial components and alloy casting aiming at reduction of harmful $\mathrm{Fe}, \mathrm{Cu}$ and $\mathrm{Ni}$ spices in the alloy.

\section{Summary and conclusions}

The formation of the homogeneous fine-grain fully recrystallized microstructure is essential for achieving the superior bio-degradability paired with good cytotoxicity and compatibility. Hot/warm severe plastic deformation promoting active dynamic recrystallization appears to be a viable tool to achieve this goal. For example, hot multi axial isothermal forging exerts the significant favorable influence on the corrosion behavior of $\mathrm{Mg}-\mathrm{Zn}-\mathrm{Zr}$ ZK60 alloy in the physiological $\mathrm{NaCl}$ solution. The formation of the homogeneous, stable and corrosion-resistant passive film on the surface of Mg-based alloys is still a challenge. The microstructure refinement by SPD leading to the increasing fraction of grain boundaries promotes the formation of a reasonably uniform protective layer, reduces the size and inhomogeneity of the second phase distribution and increases the overall corrosion resistance of the investigated ZK60 alloy. However, the properties of this protective layer are still far from being stable and further research is needed to improve it to the acceptable level.

Acknowledgements. The authors acknowledge the financial support from the Ministry of Education and Science of Russia through the contract RFMEFI58317X0070.

\section{References}

1. F. Witte, V. Kaese, H. Haferkamp, E. Switzer, A. Meyer-Lindenberg, C. J. Wirth, H. Windhagen, Biomaterials 26 (2005) 3557-3563. DOI: 10.1016/j. biomaterials.2004.09.049

2. H.H. Uhlig, R. W. Revie, Corrosion and corrosion control: an introduction to corrosion science and engineering, 3rd ed., Wiley, New York; Chichester, 1985.

3. K.U. Kainer, Magnesium alloys and technology, DGM: Wiley-VCH, Weinheim, 2003.

4. W. Xu, N. Birbilis, G. Sha, Y. Wang, J.E. Daniels, Y. Xiao, M. Ferry, Nat. Mater. 14 (2015) 1229-1235. DOI: $10.1038 /$ nmat 4435

5. N.T. Kirkland, J. Lespagnol, N. Birbilis, M.P. Staiger, Corr. Sci. 52 (2010) 287-291. DOI: 10.1016/j. corsci.2009.09.033

6. P. Doležal, J. Zapletal, S. Fintová, Z. Trojanová, M. Greger, P. Roupcová, T. Podrábský, Materials 9 (2016) 880. DOI:

\section{$10.3390 / \mathrm{ma} 9110880$}

7. E. Vasilev, M. Linderov, D. Nugmanov, O. Sitdikov, M. Markushev, A. Vinogradov, Metals 5 (2015) 2316. DOI: $10.3390 /$ met5042316

8. H. S. Brar, J. P. Ball, I. S. Berglund, J. B. Allen, M. V. Manuel, Acta Biomater. 9 (2013) 5331-5340. DOI: 10.1016/j. actbio.2012.08.004

9. M. Yamasaki, K. Hashimoto, K. Hagihara, Y. Kawamura, Acta Mater. 59 (2011) 3646-3658. DOI: 10.1016/j. actamat.2011.02.038

10. M. Yamasaki, N. Hayashi, S. Izumi, Y. Kawamura, Corr. Sci. 49 (2007) 255-262. DOI: 10.1016/j.corsci.2006.05.017

11. J. Hofstetter, E. Martinelli, A. M. Weinberg, M. Becker, B. Mingler, P.J. Uggowitzer, J.F. Löffler, Corr. Sci. 91 (2015) 29 - 36. DOI: 10.1016/j.corsci.2014.09.008

12. Y. Jang, Z. Tan, C. Jurey, Z. Xu, Z. Dong, B. Collins, Y. Yun, J. Sankar, Mater. Sci.Eng. C 48 (2015) 28-40. DOI: $10.1016 /$ j.msec.2014.11.029

13. E. Mostaed, M. Hashempour, A. Fabrizi, D. Dellasega, M. Bestetti, F. Bonollo, M. Vedani, J. Mech. Behavior of Bio. Mater. 37 (2014) 307-322. DOI: 10.1016/j. jmbbm.2014.05.024

14. E. Willbold, A. A. Kaya, R. A. Kaya, F. Beckmann, F. Witte, Mater. Sci. Eng. B, 176 (2011) 1835 - 1840. DOI: 10.1016/j. mseb.2011.02.010

15. X.-N. Gu, S.-S. Li, X.-M. Li, Y.-B. Fan, Frontiers of Mater. Sci. 8 (3) (2014) 200-218. DOI: 10.1007/ s11706-014-0253-9

16. N.T. Kirkland, N. Birbilis, J. Walker, T. Woodfield, G. J. Dias, M. P. Staiger, J. Biomed. Mater. Res. B, 95 (2010) 91 - 100. DOI: 10.1002/jbm.b.31687

17. Y.Chino, M. Kobata, H. Iwasaki, M. Mabuchi, Mater. Trans. 43 (2002) 2643 - 2646. DOI: 10.2320/matertrans.43.2643

18. F. O. Riemelmoser, M. Kuhlein, H. Kilian, M. Kettner, A.C. Hanzi, P.J. Uggowitzer, Adv.Eng. Mater. 9 (2007) 799-802. DOI: 10.1002/adem.200700161

19. H.R. Bakhsheshi-Rad, E. Hamzah, A. FereidouniLotfabadi, M. Daroonparvar, M.A. M. Yajid, M. Mezbahul-Islam, M. Kasiri-Asgarani, M. Medraj, Materials and Corrosion 65 (2014) 1178-1187. DOI: 10.1002/maco.201307588

20. F.H. Dalla Torre, A.C. Hänzi, P.J. Uggowitzer, Scripta Mater. 59 (2008) $207-210$. DOI: 10.1016/j. scriptamat.2008.03.017

21. S. Zhang, X. Zhang, C. Zhao, J. Li, Y. Song, C. Xie, H. Tao, Y. Zhang, Y. He, Y. Jiang, Y. Bian, Acta Biomater. 6 (2010) 626-640. DOI: 10.1016/j.actbio.2009.06.028

22. G. I. Morozova, V. V. Tikhonova, N. F. Lashko, Metal Sci. Heat Treat. 20 (1978) 657-660. DOI: 10.1007/ BF00780803

23. R.K. Singh Raman, S. Jafari, S.E. Harandi, Eng. Fract. Mech. 137 (2015) $97-108$. DOI: 10.1016/j. engfracmech.2014.08.009

24. X.-N. Gu, Y.-F. Zheng, Frontiers of Mater. Sci. in China 4 (2010) 111 - 115. DOI: 10.1007/s11706-010-0024-1

25. Y. Estrin, A. Vinogradov, Acta Mater. 61 (2013) 782 - 817. DOI: $10.1016 /$ j.actamat.2012.10.038

26. Vinogradov, D. Orlov, Y. Estrin, Scripta Mater. 67 (2012) 
209 - 212. DOI: 10.1016/j.scriptamat.2012.04.021

27. D. Orlov, K. D. Ralston, N. Birbilis, Y. Estrin, Acta Mater. 59 (2011) 6176-6186. DOI: 10.1016/j.actamat.2011.06.033

28. D. R. Nugmanov, O.S. Sitdikov, M. V. Markushev, Letters on Mater. 1 (2011) 213 -216. DOI: 10.22226/2410-35352011-4-213-216

29. K. Ebtehaj, D. Hardie, R. N. Parkins, Corr. Sci. 28 (1988) 811 - 821. DOI: 10.1016/0010-938X(88)90119-9

30. G. Song, A. Atrens, D. StJohn, Essential Readings in Magnesium Technology, Springer Int. Pub., Cham, 2016, pp. 565 - 572. DOI: 10.1007/978-3-319-48099-2_90

31. D. Nugmanov, O. Sitdikov, M. Markushev, Mater. Sci. For.830-831 (2015) 7-10. DOI: 10.4028/ www.scientific.net/MSF.830-831.7

32. D. R. Nugmanov, O.S. Sitdikov, M. V. Markushev, IOP Conf. Series: Mater. Sci. Eng. 82 (1) (2015) 012099. DOI: 10.1088/1757-899X/82/1/012099

33. D. R. Nugmanov, O.S. Sitdikov, M.V. Markushev, Bas. Problelms in Mater. Sci. 9 (2012) 230 - 234. DOI: 10.3390/ met5042316

34. R. Song, D. B. Liu, Y.C. Liu, W.B. Zheng, Y. Zhao, M.F. Chen, Frontiers of Mater. Sci. 8 (2014) 264-270.
DOI: $10.1007 / \mathrm{s} 11706-014-0258-4$

35. B. Ullmann, J. Reifenrath, J.-M. Seitz, D. Bormann, A. Meyer-Lindenberg, Part H, 227 (2013) 317 -326. DOI: $10.1177 / 0954411912471495$

36. Vinogradov, T. Mimaki, S. Hashimoto, R. Valiev, Scripta Mater. 41 (1999) 319-326.

37. H. Miyamoto, K. Harada, T. Mimaki, A. Vinogradov, S. Hashimoto, Corr. Sci. 50 (2008) 1215-1220. DOI: 10.1016/j.corsci.2008.01.024

38. D.-J. Lin, F.-Y. Hung, H.-J. Liu, M.-L. Yeh, Adv. Eng. Mater. (2017) 1700159. DOI: 10.1002/adem.201700159

39. N. N. Aung, W. Zhou, Corr. Sci. 52 (2010) 589 - 594. DOI: 10.1016/j.corsci.2009.10.018

40. D.-J. Lin, F.-Y. Hung, T.-S. Lui, M.-L. Yeh, Mater. Sci. Eng. C 51 (Suppl. C) (2015) 300 - 308. DOI: 10.1016/j. msec.2015.03.004

41. Q. Peng, J. Guo, H. Fu, X. Cai, Y. Wang, B. Liu, Z. Xu, Sci. Rep. 4 (2014) 3620. DOI: 10.1038/srep03620

42. S. Izumi, M. Yamasaki, Y. Kawamura, Corr. Sci. 51 (2009) 395 - 402. DOI: 10.1016/j.corsci.2008.11.003

43. A. Vinogradov, J. Mater Res. (2017) 1 - 13. DOI: $10.1557 /$ jmr.2017.268 